\section{International Scientific Journal Theoretical \& Applied Science}

p-ISSN: 2308-4944 (print) e-ISSN: 2409-0085 (online)

Year: $2014 \quad$ Issue: $10 \quad$ Volume: 18

Published: $30.10 .2014 \quad$ http://www.T-Science.org

SECTION 23. Agriculture. Agronomy. The technique.
Bair Batoevich Tsybenov senior research scientist,

State Scientific Institute «Buryat Research Institute of Agriculture» of Russian Academy of Agricultural Sciences, Ulan-Ude tzbair@yandex.ru

Alexandr Semenovich Biltuyev senior research scientist,

State Scientific Institute «Buryat Research Institute of Agriculture» of Russian Academy of Agricultural Sciences, Ulan-Ude

\title{
THE INFLUENCE OF CROPS TERMS TO THE FIELD VIABILITY OF SPRING WHEAT IN THE DRY STEPPE CONDITIONS OF BURYATIYA
}

Abstract: The results of studies of the effect of sowing dates on the field viability of spring wheat are presented in this article. The correlation field viability is defined to environmental conditions at different planting dates. The mathematical model is represented to determine it in the dry steppe zone.

Key words: crops term; variety; field viability; spring wheat; dry steppe; correlation.

Language: Russian

Citation: Tsybenov BB, Biltuyev AS (2014) THE INFLUENCE OF CROPS TERMS TO THE FIELD VIABILITY OF SPRING WHEAT IN THE DRY STEPPE CONDITIONS OF BURYATIYA. ISJ Theoretical \& Applied Science 10 (18): 28-32. doi: http://dx.doi.org/10.15863/TAS.2014.10.18.7

\section{ВЛИЯНИЕ СРОКОВ ПОСЕВА НА ПОЛЕВУЮ ВСХОЖЕСТЬ ЯРОВОЙ ПШЕНИЦЫ В СУХОЙ СТЕПИ БУРЯТИИ}

Аннотация: Представлень результаты исследований влияния сроков посева на полевую всхожесть яровой пшеницы. Определены корреляционные связи полевой всхожести с экологическими условиями при разных сроках посева. Предложены математические модели ее определения в сухостепной зоне.

Ключевые слова: срок посева; сорт; полевая всхожесть; яровая пшеница; сухая степь; корреляция.

\section{Введение}

Полевая всхожесть семян - один из основных элементов, формирующих продуктивность зерновых культур. Этот показатель определяется комплексом факторов: посевными качествами семян, системой обработки почв, экологическими условиями прорастания семян. В Западном Забайкалье полевая всхожесть яровой пшеницы варьирует в пределах 50-70\%.

Для нормального прорастания семян пшеницы необходимо наличие и благоприятное сочетание влаги, тепла и кислорода. В этом случае период от посева до всходов будет минимальным [4; 10].

По мнению ряда авторов $[1 ; 3 ; 7 ; 8]$ главным фактором, определяющим уровень полевой всхожести зерновых культур в условиях сухостепной зоны Бурятии, являются запасы продуктивной влаги в почве. Ее содержание, необходимое для получения удовлетворительных всходов, в легкосуглинистой почве по данным [8] составляет 3-4 мм. Начало прорастания семян яровой пшеницы отмечается при температуре 1$4{ }^{\circ} \mathrm{C}$, но оптимальной температурой для начала ферментативной деятельности и обмена веществ в семенах является $14-16{ }^{\circ} \mathrm{C}$, а для роста зародышевых корней - 9-16 ${ }^{\circ} \mathrm{C}$. Под влиянием низкой температуры интенсивность расходования запасных веществ эндосперма на рост проростков уменьшается, что ведет к снижению их начального роста и способности преодолевать сопротивление почвы при выходе их на дневную поверхность [5]. В фазе становления проростка, при быстром нарастании тепла весной и резком возврате холодов, а иногда и заморозков, что часто наблюдается в условиях Восточной Сибири, в т.ч. Забайкалья, могут погибнуть до 50\% и более проростков [10].

\section{Условия и методика исследований}


Полевые опыты проводились в 2006-2008 гг. на опытном стационаре Бурятской ГСХА им. B.P. Филиппова в сухостепной зоне Бурятии.

Почвенный покров опытного стационара представлен каштановыми типичными аккумулятивно-карбонатными малогумусовыми $(1,28 \%)$ почвами, которые характеризовались содержанием 168 мг/кг почвы подвижного фосфора, 157 мг/кг обменного калия (по Чирикову) и 3,2 мг/кг почвы нитратного азота.

Климат зоны резко континентальный, с засушливым летом и малоснежной зимой. Среднемноголетняя сумма осадков за период май-сентябрь составляет 201 мм, а сумма температур выше $10{ }^{\circ} \mathrm{C}-1500-2100{ }^{\circ} \mathrm{C}$. Метеорологические условия в годы исследований по характеру распределения осадков отличались от многолетней нормы. Так, в 2006 г. за май-сентябрь общее количество осадков превысило среднемноголетнюю норму на 41,4 мм. Большая часть осадков (57\%) выпала за период с III декады июня по III декаду июля преимущественно в виде ливневых осадков. В августе дефицит осадков составил $24,5 \%$ от среднемноголетней нормы.

В течение вегетационного периода 2007 г. сложились неблагоприятные условия для роста и развития культур в связи с летней засухой. Количество осадков составило $74,5 \%$ от среднемноголетней нормы (151,3 мм). При этом в первой половине вегетации (май-июнь) осадков выпало на 63,8\% больше нормы, а в июле-августе их количество составило $33,6 \%$ от нормы за этот период. Почти четверть всей суммы осадков $(23,5 \%)$ пришлась на сентябрь.

В 2008 г. количество осадков составило 222,3 мм (на 10,6\% выше нормы). В июне-июле количество осадков превысило норму на 83,2\%, а в августе-сентябре, в период налива зерна и уборки урожая, их количество составило $39,1 \%$ от многолетней нормы.

Значительно различались условия вегетации и по теплообеспеченности. Среднесуточная температура воздуха за летний период во все годы исследований была выше нормы: в 2006 г. - на $1,2{ }^{\circ} \mathrm{C}$, в 2007 - на $2,6{ }^{\circ} \mathrm{C}$, а в 2008 - на $1,3{ }^{\circ} \mathrm{C}$. Соответственно сумма эффективных температур выше $10{ }^{\circ} \mathrm{C}$ составляла $1877,3,2257,0$ и $2021,2^{\circ} \mathrm{C}$.

Агротехника в опытах принята в соответствии [9]. Объектами исследований в опыте были районированные сорта. Посев проводился по чистому пару с нормой высева 4 млн. шт. всхожих семян на гектар. Делянки размещались методом рендомизированных повторений в два яруса, в четырехкратной повторности, с учетной площадью 56 м². Уборка проводилась комбайном Sampo-500. Данные урожая приведены к 14\%-ной влажности и 100\%ной чистоте.

В полевых опытах проводились следующие наблюдения и учеты: фенологические наблюдения, определение густоты стояния растений в фазу полных всходов, анализ элементов структуры урожая - по методике [6]; определение качества зерна яровой пшеницы проведено по соответствующим стандартам. Экспериментальные данные подвергались математической обработке по общепринятым методикам [2], а также с помощью пакета анализа данных программ Excel и Snedecor.

\section{Результаты исследований}

В наших опытах среднесуточная температура воздуха за период посев - всходы при раннем сроке посева в 2006 г. была минимальной и составляла $8,6{ }^{\circ} \mathrm{C}$. Ко второму сроку посева данный показатель был уже равен $11,3{ }^{\circ} \mathrm{C}$, а во время позднего срока посева увеличился еще на $1,7{ }^{\circ} \mathrm{C}$. В 2007 г. при всех сроках посева в связи с более ранним наступлением весны теплообеспеченность была значительно выше. Так, при раннем сроке посева средняя температура за период от посева до полных всходов составляла $11,5^{\circ} \mathrm{C}$, тогда как в 2008 г. за этот же период она была равна $9,8{ }^{\circ} \mathrm{C}$. Прорастание семян при позднем сроке посева в 2007 г. проходило при среднесуточной температуре $14,2{ }^{\circ} \mathrm{C}$ при ее варьировании от 6,0 до $17,8{ }^{\circ} \mathrm{C}$, причем первая половина этого периода отличалась большими значениями показателя - в последней пятидневке мая температура возросла до $15,2^{\circ} \mathrm{C}$, а в начале июня вновь понизилась до $10,5^{\circ} \mathrm{C}$.

Сложившиеся гидротермические условия за период исследований обеспечивали получение неравномерных всходов, как по годам, так и по срокам посева (табл. 1). Дисперсионный анализ выявил достоверные различия по фактору А только лишь между средним и поздним сроками посева, который в условиях сухостепной зоны существенно снижает полевую всхожесть сортов яровой пшеницы. Между вариантами фактора В достоверных различий выявлено не было. В среднем за три года варьирование показателя полевой всхожести $(\mathrm{V}, \%)$ у всех сортов было наибольшим при раннем сроке посева, кроме сорта Бурятская остистая, который отличался наибольшей изменчивостью признака при позднем сроке посева.

Если рассматривать реакцию сортов на изменение сроков их посева, то видно, что наиболее благоприятные условия для всех сортов наблюдались при раннем и среднем сроках посева в 2008 г., когда средние показатели полевой всхожести были равны 71,7 и 68,9\%, соответственно. Самые неблагоприятные 
условия были в 2006 г. при раннем сроке посева и в 2007 г. при посеве в поздний срок.

В 2006 г. в среднем по сортам при раннем сроке посева полевая всхожесть составляла $50,0 \%$, что на 4,2\% было меньше, чем на контроле (средний срок посева), а при переносе срока посева на третью декаду мая всхожесть увеличилась на 4,2\% по сравнению с ним. Наибольший показатель полевой всхожести, среди всех вариантов в этот год, был отмечен у сорта Бурятская остистая при позднем сроке его посева $(75,5 \%)$.

В 2007 г. полевая всхожесть при раннем и среднем сроках посева была выше, чем в 2006 г., но значительно уступала показателям этих вариантов в 2008 г.

Снижение полевой всхожести пшеницы от раннего срока посева к позднему и несущественная разница по этому показателю между ранним и средним сроками объясняется, по-нашему мнению, большими запасами продуктивной влаги при ранних посевах и отсутствием значимых осадков вплоть до середины второй декады июня на фоне резкого повышения температуры воздуха во второй декаде мая и понижения ее к концу месяца.

Полевая всхожесть сортов яровой пшеницы, \%, 2006-2008 гг.

\begin{tabular}{|c|c|c|c|c|c|c|}
\hline \multirow{2}{*}{$\begin{array}{c}\text { Срок посева } \\
\text { (фактор А) }\end{array}$} & \multirow{2}{*}{$\begin{array}{c}\text { Сорт } \\
\text { (фактор B) }\end{array}$} & \multicolumn{3}{|c|}{ Год } & \multirow[t]{2}{*}{$\mathbf{M} \pm \mathbf{m}$} & \multirow[t]{2}{*}{$\mathrm{V}, \%$} \\
\hline & & 2006 & 2007 & 2008 & & \\
\hline \multirow{5}{*}{ ранний } & Селенга (контроль) & 48,9 & 65,2 & 73,5 & $62,6 \pm 5,9$ & 16,3 \\
\hline & Бурятская остистая & 59,1 & 66,5 & 72,8 & $66,4 \pm 3,2$ & 8,4 \\
\hline & Арюна & 52,2 & 66,1 & 72,3 & $63,5 \pm 4,9$ & 13,3 \\
\hline & Тулайковская степная & 45,1 & 56,0 & 70,1 & $57,3 \pm 5,9$ & 17,9 \\
\hline & Новосибирская 29 & 44,6 & 58,3 & 69,6 & $57,4 \pm 5,9$ & 17,8 \\
\hline \multicolumn{2}{|c|}{ Среднесортовая по сроку посева } & 50,0 & 62,4 & 71,7 & $61,4 \pm 5,1$ & 14,4 \\
\hline \multirow{5}{*}{$\begin{array}{c}\text { средний } \\
\text { (контроль) }\end{array}$} & Селенга (контроль) & 48,8 & 58,7 & 68,9 & $58,8 \pm 4,7$ & 13,9 \\
\hline & Бурятская остистая & 61,7 & 62,5 & 67,0 & $63,8 \pm 1,4$ & 3,7 \\
\hline & Арюна & 60,1 & 63,3 & 68,5 & $64,1 \pm 2,0$ & 5,4 \\
\hline & Тулайковская степная & 48,6 & 60,5 & 69,7 & $59,5 \pm 5,0$ & 14,5 \\
\hline & Новосибирская 29 & 51,9 & 58,5 & 70,1 & $60,6 \pm 4,3$ & 12,4 \\
\hline \multicolumn{2}{|c|}{ Среднесортовая по сроку посева } & 54,2 & 60,7 & 68,9 & $61,4 \pm 3,5$ & 9,8 \\
\hline \multirow{5}{*}{ поздний } & Селенга (контроль) & 53,0 & 48,5 & 58,2 & $53,3 \pm 2,3$ & 7,4 \\
\hline & Бурятская остистая & 75,5 & 56,6 & 57,6 & $63,7 \pm 5,0$ & 13,6 \\
\hline & Арюна & 55,6 & 47,2 & 55,3 & $52,9 \pm 2,2$ & 7,3 \\
\hline & Тулайковская степная & 51,7 & 58,3 & 50,8 & $53,3 \pm 1,9$ & 6,3 \\
\hline & Новосибирская 29 & 56,3 & 45,2 & 49,5 & $50,7 \pm 2,6$ & 9,0 \\
\hline \multicolumn{2}{|c|}{ Среднесортовая по сроку посева } & 58,4 & 51,2 & 54,3 & $54,8 \pm 1,7$ & 5,4 \\
\hline \multicolumn{2}{|c|}{$\begin{array}{l}\text { НСР (уровень значимости) } \\
\text { для фактора А - }\end{array}$} & & & жакте & твия АВ - & \\
\hline
\end{tabular}

Поздний срок посева попадает в наиболее худшие условия по сравнению с предшествующими сроками, так как первая декада июня, когда отмечалось массовое появление всходов, отличалась высокой температурой воздуха, снижением запасов влаги в почве до уровня В3 и практически полным отсутствием осадков. По-видимому, осадки третьей декады мая при резком повышении температуры воздуха, низкой его относительной влажности очень быстро испаряются с открытой поверхности почвы, чему также способствуют усиливающиеся в это время ветра.

Изучение сопряженности показателя полевой всхожести со среднесуточной температурой почвы на глубине 20 см, среднесуточной температурой воздуха, количеством атмосферных осадков, продолжительностью периода посев - всходы, количеством продуктивной влаги в пахотном слое почвы, ее содержанием в слое 0-50 см, температурным градиентом (разница температуры почвы и воздуха), а также ГТК Селянинова, оцениваемых за период посев всходы, показало, что при раннем сроке посева у всех сортов наблюдается сильная корреляционная связь с осадками и с суммой положительных температур $>10{ }^{\circ} \mathrm{C}$ за этот период. Статистически достоверной оказалась связь с суммой температур у всех сортов кроме сорта Тулайковская степная. Таким образом, при раннем посеве ощущается недостаток тепла для 
прорастания, что также подтвердилось при проведении регрессионного анализа. Зависимость от осадков за этот период была существенной у сортов Селенга и Арюна. Значение коэффициента снижалось у сортов Бурятская остистая и Новосибирская 29 (r = 0,91), а у сорта Тулайковская степная он был самым низким $(\mathrm{r}=0,85)$. Возможно, это говорит о том, что данный сорт требует меньше тепла и влаги для прорастания и формирования проростков в силу его генетических особенностей. Аналогичная картина открылась, когда мы проверили корреляционные связи полевой всхожести с подекадными показателями основных метеорологических и почвенных характеристик за май месяц. Так, зависимости полевой всхожести от температуры воздуха и температуры почвы на глубине 20 см во второй декаде мая оказались сильными прямыми и достоверными у всех сортов, кроме сорта Тулайковская степная по обоим показателям, и сортов Бурятская остистая и Новосибирская 29 с температурой почвы. Анализ связи полевой всхожести с количеством продуктивной влаги в почве на момент посева также показал, что и эта корреляционная зависимость была достоверной у всех сортов кроме Тулайковской степной.

Очень слабая связь у всех сортов с осадками первой декады мая, в силу их отсутствия, во вторую декаду месяца возросла до очень сильной, но достоверной была только у сорта Арюна $(\mathrm{r}=0,95)$. Такие же показатели были получены при анализе зависимости полевой всхожести от суммы осадков за период посев - всходы. Существенная корреляционная связь отмечалась только у сортов Арюна и Селенга. Этот факт наталкивает на мысль, что эти сорта более требовательны по сравнению с другими изученными сортами к условиям увлажнения и теплообеспеченности за период посев - всходы.

Необходимо отметить, что при раннем сроке посева прослеживалась еще одна общая для всех сортов особенность - обратная и средней силы $(\mathrm{r}=-0,44 \ldots-0,68)$ корреляционная связь с продолжительностью периода посев - всходы, которая от раннего срока посева к позднему сокращалась, в среднем за три года, на 5 дней с колебаниями от 4 до 7 дней.

Проведение регрессионного анализа позволило нам определить уравнение связи полевой всхожести с выявленными предикторами.

$\mathrm{R}^{2}=0,98$

ПВ $\mathrm{c}_{1}=-44,460+16,374 \mathrm{tB}_{5 / 2}-6,358 \mathrm{t}_{5 / 2}$ при

где: ПВ $\mathrm{c}_{1}$ - полевая всхожесть при раннем сроке посева, \%; tв $5 / 2$ - температура воздуха за вторую декаду мая, ${ }^{\circ} \mathrm{C}$; tпा/2 - температура почвы на глубине 20 см за вторую декаду мая, ${ }^{\circ} \mathrm{C}$.

Средний срок посева (вторая декада мая) в наших исследованиях был принят за контрольный вариант фактора А (срок посева). Установление корреляционных связей полевой всхожести яровой пшеницы, высеянной в этот срок, с показателями тепло- и влагообеспеченности за весенне-раннелетний период привело к построению линейной модели следующего вида:

$\Pi B c_{2}=99,387-2,802 \mathrm{tB}_{5 / 1-2}-1,103 \mathrm{w}_{5 / 1-2}-$ $6,983 \Gamma{ }^{-1 / 1-2}$ при $\mathrm{R}^{2}=0,99$

где: ПВ $c_{2}$ - полевая всхожесть при среднем сроке посева, \%; tв5/1-2 - среднесуточная температура воздуха за первую и вторую декады мая, ${ }^{\circ} \mathrm{C}$;

$\mathrm{W}_{5 / 1-2}$ - количество осадков за первую и вторую декады мая, мм; ГТК $5 / 1-2$ - гидротермический коэффициент Селянинова за первую и вторую декады мая.

При позднем сроке посева полевая всхожесть яровой пшеницы также выражалась линейной моделью: $=0,99$

$\Pi B c_{3}=35,65+1,45 \mathrm{tB}_{6 / 1}-0,543 \Pi B_{5 / 3}$ при $\mathrm{R}^{2}$

где: ПВ с 3 - полевая всхожесть при позднем сроке

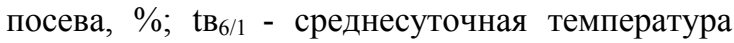
воздуха за первую декаду июня, ${ }^{\circ} \mathrm{C}$; $3 \mathrm{HB}_{5 / 3}$ запасы продуктивной влаги в третьей декаде мая, MM.

В среднем за три года наших исследований в изменчивость показателя полевой всхожести яровой пшеницы в сухой степи наибольший вклад вносили метеорологические условия года $(23,7 \%)$, срок посева $(11,7 \%)$ и их совместное влияние, которое увеличивается до $38,2 \%$. Заметное влияние оказывали сортовые особенности (рис. 1). 


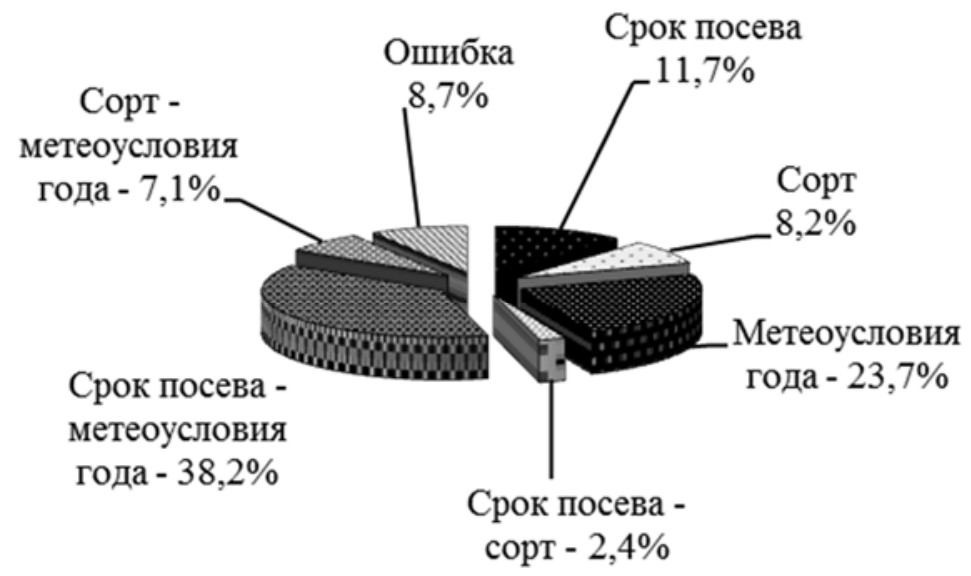

\section{Рисунок 1 - Доля влияния различных факторов на изменчивость полевой всхожести яровой пшеницы, 2006-2008 гг.}

\section{Заключение}

Сорт Селенга, принятый за контроль, в среднем за три года хорошо отреагировал на ранний срок посева - показатель полевой всхожести в этом варианте был наибольший $(62,6 \%)$, при позднем посеве его всхожесть снижалась на 9,3\% по сравнению с ранним и на 5,5\% по сравнению со средним сроком посева.

Сорт Бурятская остистая в среднем за время исследований превосходил контроль и все остальные сорта при раннем и позднем сроках посева, а при среднем сроке посева превосходил контроль (на 5,0\%), но уступал сорту Арюна. Сорта Новосибирская 29 и Тулайковская степная при всех сроках посева уступали по этому показателю не только контролю, но и другим сортам, однако различия оказались несущественными.

Наибольший вклад в изменчивость полевой всхожести яровой пшеницы вносят метеоусловия года $(23,7 \%)$, срок посева $(11,7 \%)$ и их совместное влияние $(38,2 \%)$.

\section{References:}

1. Dambaeva ZB, Osipov VI (1998) Sorta i tehnologija vozdelyvanija zernovyh kul'tur v Burjatii. - Ulan-Udje, 36.

2. Dospehov BA (1985) Metodika polevogo opyta (s osnovami statisticheskoj obrabotki rezuljtatov issledovanij) Moscow: Agropromizdat, 351.

3. (2002) Zernovoe pole Burjatii: Metodicheskie rekomendacii MSHiP RB, Burjatskij NIISH SO RASHN. - Ulan-Udje, 52.

4. Korobcev II (1968) Izrezhivanie posevov pshenicy i bor'ba s nim. Ulan-Udje: Burjat. kn. izd-vo, 91.

5. Korovin AI (1984) Rastenija i jekstremal'nye temperatury. L.: Gidrometeoizdat, 272.
6. (1989) Metodika gosudarstvennogo sortoispytanija sel'skohozjajstvennyh kul'tur. Moscow, Vyp. 2, 194.

7. Nikolaev AD (1970) Predshestvenniki jarovoj pshenicy na legkih kashtanovyh pochvah Burjatskoj ASSR: Avtoref. diss. kand. s.-h. nauk, Ulan-udje, 28.

8. Osipov VI (1982) Zernovye kul'tury v Burjatii. - Ulan-Udje, 88.

9. (1989) Sistema zemledelija Burjatskoj ASSR: Rekomendacii. VASHNIL, Sibirskoe otdelenie. Burjatskij NIISH. - Novosibirsk, 332.

10. (1998) Jarovaja pshenica v Vostochnoj Sibiri (biologija, jekologija, selekcija i semenovodstvo, tehnologija vozdelyvanija) Pod red. N.G. Vedrova; Krasnojarskij gos. agrar. un-t. - Krasnojarsk, 312. 